\title{
Genetic evaluations for measures of the milk-flow curve in the Italian Brown Swiss population
}

\author{
K. A. Gray, ${ }^{\star}$ F. Vacirca, $†$ A. Bagnato, $\dagger^{1}$ A. B. Samoré, $†$ A. Rossoni, $\neq$ and C. Maltecca \\ *North Carolina State University, Department of Animal Science, Box 7621, NCSU Campus Raleigh 27695 \\ †Universitá degli studi di Milano, Department of Veterinary Sciences and Technologies for Food Safety, via D. Trentacoste 2, 20134 Milano, Italy \\ łItalian Brown Breeders Association, Loc. Ferlina 204, Bussolengo 37012, Italy
}

\section{ABSTRACT}

The objective of this study was to estimate heritabilities and genetic correlations between milk-release parameters, somatic cell score, milk yield, and udder functional traits in the Italian Brown Swiss population. Data were available from 37,511 cows over a span of 12 yr (1997-2008) from 1,592 herds. Milking flows were recorded for each individual once during lactation. Three different analyses were performed to estimate variance components for all the traits of interest. The first analysis included single control data milk yield, somatic cell score, maximum milk flow, average milk flow, time of plateau, decreasing time, and total milking time, whereas the second analysis included milkrelease parameters as well as total udder score, udder depth, and 305-d milk yield and somatic cell score as dependent variables. The third analysis included total milking time, 305-d milk yield and somatic cell score, total udder score, udder depth, and ratios of maximum milk flow over total milking time (R1), time of plateau (R2), and decreasing time (R3) to estimate the relationship between the shape of the milk-release curves and important milking traits. Results from the first and second analysis found similar heritabilities for milkability traits ranging from 0.05 to 0.41 with genetic correlations between production traits and flow traits ranging from low to moderate values. Positive genetic correlations were found among production, somatic cell score, and milkability traits. The third analysis showed that $\mathrm{R} 1 \mathrm{had}$ the greatest heritability of the ratio traits (0.37) with large genetic correlations with R2 and R3, a low correlation with 305-d somatic cell score, and no correlation with 305-d milk yield. Estimated responses to selection over 5 generations were also calculated using different indexes, which included either flow or ratio traits. The results of this study show that it is possible to use information collected through portable flowmeters to improve milkability traits. Using a set of

Received September 22, 2009.

Accepted May 3, 2010.

${ }^{1}$ Corresponding author: alessandro.bagnato@unimi.it variables or traits to describe the overall release of milk can be an advantageous selection strategy to decrease management costs while maintaining milk production. Key words: milkability, dairy cattle, genetic improvement

\section{INTRODUCTION}

Milkability belongs to the group of traits termed functional traits, which also includes health, feed efficiency, fertility, and calving ease. Milkability can be defined as the ease of milking of dairy cows. This trait is usually measured as milking speed, either recorded objectively or through subjective measurement (Meyer and Burnside, 1987; Sandrucci et al., 2007).

Other indicators of milkability include flow measures such as average milk flow (AVGF) and maximum milk flow (MMF; Guler et al., 2009). Milkability measures, either as milking flow or speed, have long been recognized as relevant criteria in animal selection (Miller et al., 1976; Bruckmaier et al., 1995) due to their effect on management costs of milking cows (Groen et al., 1997). An increase of MMF and AVGF and a reduction of total milking time (TMT) results in a reduction of milking labor time and an increase in the efficiency of the automatic milking system (Dodenhoff et al., 1999b). Considering that labor accounts for a large fraction of the total costs of milk production, it is not a surprise that Prints et al. (2002) estimated economic values for milking time expressed as euro/min per cow per yr ranging from $€ 1.63$ to 25.97 , depending on the size of milking parlor.

Furthermore, milkability traits have been indicated as the third most important variable, after milk yield and fat content, affecting a farmer's net profit (Sivarajasingam et al., 1984; Meyer and Burnside, 1987) and consequently the culling rate (Bagnato et al., 2003). The association between milking speed, SCS, and clinical mastitis incidence is controversial. High levels of SCS have been generally associated with fast milking on the basis of both subjective measures (Lund et al., 1994; Boettcher et al., 1998) and electronic measures (Zwald et al., 2005; Samoré et al., 2009). Rupp and Boichard 
(1999) estimated a similar relationship between milking speed and SCS but a nonsignificant relationship with clinical mastitis incidence, whereas Wiggans et al. (2007) reported correlation values of -0.14 and -0.40 for different EBV reliability levels, associating fast milking with lesser values of SCS. Samoré and Groen (2006) detected a nonlinear relationship between breeding values of bulls, associating the average values for SCS with classes of milking-speed EBV in Italian Holsteins, although the correlation between EBV of 0.07 evidenced a small but unfavorable relationship.

Although flow measures represent an improvement over the subjective scoring or the direct measure of milking time, they can only describe one aspect of milkability, and other factors should be considered. In particular, some studies have found ties between characteristics of milk-emission curves and SCS. Several authors (Naumann et al., 1998; Sandrucci et al., 2007; Tancin et al., 2007) reported a significant correlation between duration of the different phases of milk release and SCC in milk. A recent study by Zucali et al. (2009), performed on primiparous Holstein cows, confirmed that high SCC are significantly correlated with greater flow (average and maximum) along with a longer decline phase during milking time.

In recent years different policies have been adopted by countries and breeders associations regarding the inclusion of milkability traits in selection criteria. The interest in including milkability variables in a selection index has recently increased due to the possibility of comparing sires internationally for this trait. Bagnato et al. (2007) evaluated the feasibility of multiple-trait across-country evaluation EBV estimation for Brown Swiss for milkability, and a routine international multiple-trait across-country evaluation has been available for this trait since January 2009 (Interbull, 2008).

Recently, the Italian Brown Breeders Association has adopted AVGF as the measure of choice in its genetic evaluations. However, in Italian Brown Swiss, AVGF has some unfavorable correlations with important functional traits, particularly SCS (0.46) and uddertype traits such as udder depth $(-0.25$; Ghiroldi et al., 2005).

Milkability studies to date have taken into account one or more measures of release during milking time. It is likely though that the overall milking-emission curve rather than a specific measure would better model milk emission for the purpose of evaluating its relationship with production and functional traits. Rossoni (2002) investigated the variation of parameters describing the milking-emission curves within lactation for the same individual and across parities to investigate the relationship between curve shapes, production, and SCC. In Rossoni's study, a simplified model for the milk released at each single milking can be interpreted as a combination of maximum milk flow and length of stable flow. Those measures appear to be relatively stable across parities and stages of lactation, with repeatabilities for MMF and time at plateau (TP) of 0.68 and 0.50 , respectively, therefore, characterizing a sort of milk-emission fingerprint for each individual.

The aim of this study was to evaluate the possibility of including different milkability measures in the selection program for the Italian Brown Swiss population. The following steps were considered: i) estimation of heritabilities and correlations for milk release and production traits obtained from a single control in a large Italian Brown Swiss population, ii) estimation of heritabilities and correlations for single milk flow data with $305-d$ production traits and conformation traits, and iii) investigation of correlated responses for production and functional traits with the use of different milk flow traits in a selection index.

\section{MATERIALS AND METHODS}

Data for the study were provided by the Italian Brown Breeders Association. The data included information spanning a 12-yr period (1997 to 2008).

\section{Flow Data}

Milking flows were recorded once for each individual during a single lactation using a portable milk flow recorder (LactoCorder, WMB AG, Balgach, Switzerland). Milk flow characteristics were detected every 0.7 $\mathrm{s}$ and saved at intervals of $2.8 \mathrm{~s}$ (WMB, 2005).

The flow profile can be divided into 6 phases: 1) ascending time defined as the period spanning from a milk flow greater than $0.5 \mathrm{~kg} / \mathrm{min}$ until TP; 2) TP defined as steady milk flow; 3) decreasing time (DT) spanning from the end of TP (i.e., declining flow) until milk flow is below $0.2 \mathrm{~kg} / \mathrm{min}$; 4) overmilking time defined as the time between a milk flow below $0.2 \mathrm{~kg} / \mathrm{min}$ and the group removal; 5) stripping time defined as a period, at the end of milking, with milk flow greater than 0.2 $\mathrm{kg} / \mathrm{min}$ and lasting for at least $4.2 \mathrm{~s}$; and 6) overmilking time after stripping defined as the time between a milk flow below $0.2 \mathrm{~kg} / \mathrm{min}$ and the group removal after stripping time. The overall sum of all the periods corresponds to TMT. In addition, MMF was recorded as the maximum flow preceding the TP.

To estimate variance components and genetic correlations between milk flow traits and production records, 2 models were applied. In the first model, a single measure of both flow and production traits was investigated, whereas in a second analysis, milk flow measures were analyzed in a model including functional 
traits and 305-d data for production traits (see details below).

\section{Production Traits}

Single control production traits included daily milk production (TD-MY) and SCC collected during the routine milk recording scheme. Because these data were not always taken contemporarily to flow measurements, the routine milk recording closest to the flow measurement was retained in the analysis. Because routine milk recording occurred every $28 \mathrm{~d}$, the maximum distance between flow data and TD-MY and SCC was $14 \mathrm{~d}$. Raw SCC data were converted to SCS following the procedures of Wiggans and Shook (1987), and single control SCS (TD-SCS) measures were then employed in the analysis. Lactation data (305 d) included 305-d milk yield (305-MY) and individual SCC averaged within lactation and transformed into SCS (305-SCS) as in Samoré et al. (2009).

\section{Functional Traits}

Functional traits considered in the lactation data analysis included only traits showing unfavorable correlation with AVGF (Ghiroldi et al., 2005) in the Italian Brown Swiss Total Economic Index (ITE). These traits included udder depth (UD), or a trait directly related to the udder health of the individual, such as total udder score (TUS).

\section{Data Editing}

The original data set consisted of 66,874 observations of 47,579 Italian Brown Swiss cows distributed over 1,794 herds. All the cows in a herd, at the visit of the technician, were recorded for milk-flow measures. A minority of individuals $(\sim 5 \%)$ had multiple observations, and for those animals, only the most recent observation was retained. The use of oxitocyn was recorded on each individual at milk-flow measurement, and records of treated cows were deleted. Observations with missing production or flow data were deleted. To target potential problems in the structure of flow data, the combination of production and flow measures, in relation to the stage of lactation, was investigated for each cow. Animals with inconsistent patterns (e.g., with very high yield and extremely short milking time at a late stage of lactation) were further inspected and possibly eliminated from the data set. The general editing criteria adopted in the study are depicted in Figure 1. Data editing resulted in a sizable loss of data. There could be several reasons for this that could be related to both data collection, namely the incorrect pairing of test-day production and milk-flow measurements, and technical problems in the recording of one or more parameters either caused by the portable flowmeter itself or by the technician's handling. Given that the scope of the present study was the estimation of variance components, very conservative data editing was applied. Nonetheless, the effects of data editing of flow measurements on breeding-value estimation were further investigated. A series of single control models was fitted by relaxing one editing criterion at a time, and rank correlations between the top 150 sires in each analysis were obtained. In the final data set, at least 2 records per each level of the herd-year-month-of-test class were guaranteed. The final data set consisted of 37,511 records from cows that were daughters of 2,322 sires and 30,315 dams distributed over 1,592 herds (Table 1). Descriptive statistics of the data set are shown in Table 2. Pedigree information included 1,018,284 individuals spanning 7 generations. For the analysis based on 305-d data, lactations shorter that $250 \mathrm{~d}$ and all 305-MY more than 3.5 standard deviations less than the mean 305-MY were discarded.

\section{Data Analyses}

Three separate analyses were performed. The analyses were aimed at obtaining estimates of variance components and correlations for flow and production traits.

Single Control Analysis. A 7-trait animal model was fitted:

$$
\begin{aligned}
y_{i j k l m n o} & =\mu+P_{i}+H_{j}+Y M_{k}+\beta_{1} A F C_{l} \\
& +\beta_{2} D I M_{m}+a_{n}+e_{i j k l m n o},
\end{aligned}
$$

where $y_{i j k l m n o}=$ dependent variables: TD-MY, TD-SCS, MMF, AVGF, TP, DT, and TMT; $\mu=$ factor common to all observations; $P_{i}=$ fixed effect of parity (2 levels, first and later parities); $H_{j}=$ fixed effect of herd $(1,592$ levels); $Y M_{k}=$ random effect of year-month of test; $A F C_{l}=$ covariate of age of cow at first calving (mo); $D I M_{m}=$ covariate of DIM; $\beta_{1}$ and $\beta_{2}=$ linear regression coefficients for $A F C_{l}$ and $D I M_{m}$, respectively; $a_{n}=$ additive genetic random effect of animal; $e_{i j k l m n o}$ $=$ random residual error. Standard distributional assumptions for year-month of test, additive genetic, and residual variances were employed.

305-d Analyses. To estimate genetic correlations of milk flow records with 305-d production, a second 9 -trait animal model was applied. The model was similar to the previous model, with the substitution of a fixed year-season effect (117 levels) for the random year-month-of-testing effect previously fitted. In this case, the traits included in the model were MMF, 


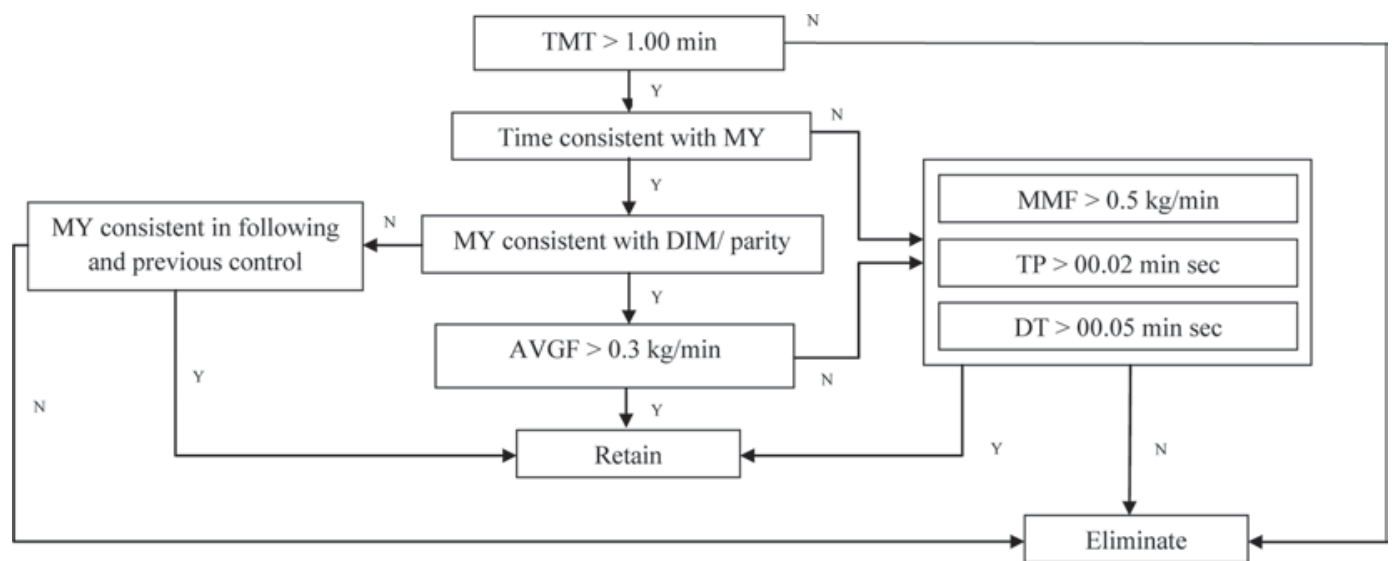

Figure 1. Data editing scheme for flow and time measures. Editing based on production or pedigree is not included. TMT $=$ total milking time; $\mathrm{MY}=$ milk yield; $\mathrm{AVGF}=$ average milk flow; $\mathrm{MMF}=$ maximum milk flow; $\mathrm{TP}=$ time of plateau; $\mathrm{DT}=\mathrm{decreasing}$ time; $\mathrm{Y}=$ yes; $\mathrm{N}$ $=$ no.

AVGF, TP, DT, TMT, 305-MY, 305-SCS, TUS, and UD.

In this analysis, single control flow measures were coupled with lactation measures of production. Ideally, repeated observations of flow over the course of a lactation should be included in the model. Inclusion of repeated measures would result in greater accuracies of the breeding values estimated, particularly if repeatability for some or all flow traits was low. Currently, data collection in the Italian Brown population does not include multiple recordings of flow measurements. Nonetheless in the original data set, multiple observations were available for a subsample of 4,737 cows, daughters of 285 sires (mean $=2.45$ observations). These data were employed in a separate analysis to obtain an indication of the repeatability for the flow measures and gauge what advantage might be achieved with the inclusion of multiple measures of flow. The model employed was similar to the one in the 305-d analysis, with the inclusion of an extra random permanent environmental effect. Due to convergence problems, this analysis was restricted to flow and production traits only.

Finally, fitting a covariate for DIM will account for differences in stage of lactation for flow parameters. The regression coefficient is, in this case, obtained from the range of DIM present in the current data. Estimates from a reliable sample of individuals with repeated measures covering a larger spectrum of DIM within the same lactation could improve the model fit. To investigate this possibility, a model similar to the one in the 305-d analysis, in which milk-flow traits were preadjusted for the stage of lactation, was fitted. Adjustments were performed as

$$
y^{*}=y_{i}+(180-i) \times \beta,
$$

where $y^{*}$ is the adjusted trait of interest, $y_{i}$ is the unadjusted trait collected at the $i$ th day of lactation, and $\beta$ is the linear regression coefficient. In this case, the linear regression parameters were estimated using the GLM procedure of SAS (SAS Inst. Inc., Cary, NC) from an independent sample of 210 individuals with an average of 11.32 repeated milk-release measures (minimum DIM $=2$, maximum DIM $=400$ ) collected throughout the course of an entire lactation. The model with preadjustments substituted for the DIM covariate yielded similar results and is not discussed in the following sections.

Ratios Analysis. The flow of milk during milking operations can be divided into approximately 3 phases: increasing, stable, and decreasing. To provide a description, albeit approximate, of how the shape of milk-release curves affects milkability, production, and functional traits, the following ratios were calculated: MMF:TMT (R1), MMF:TP (R2), and MMF:DT (R3).

Given that MMF is the numerator for all ratios, an increase of any of the ratios will correspond to an

Table 1. Number of observations for the different analyses

\begin{tabular}{lcc}
\hline Variable & $\begin{array}{c}\text { Observations } \\
\text { for single } \\
\text { control analysis }\end{array}$ & $\begin{array}{c}\text { Observations f } \\
\text { or 305-d } \\
\text { analysis }\end{array}$ \\
\hline Total observations & 37,511 & 30,952 \\
Total first lactations & 12,350 & 10,513 \\
Total herds & 1,592 & 1,496 \\
Total sires & 2,322 & 2,107 \\
Total dams & 30,315 & 25,844 \\
Dams with offspring & 7,790 & 5,831 \\
in the data set & & \\
\hline
\end{tabular}

${ }^{1}$ The $305-\mathrm{d}$ data available for use in analyses of flows and ratios. 
Table 2. Descriptive statistics of the data set

\begin{tabular}{lcccc}
\hline Variable $^{1}$ & Minimum & Maximum & Mean & SD \\
\hline AFC (mo) & 19.07 & 45.50 & 30.67 & \pm 6.25 \\
DIM & 5.00 & 365.00 & 159.20 & \pm 98.30 \\
TD-MY (kg) & 5.01 & 37.81 & 11.85 & \pm 3.62 \\
305-MY (kg) & 2,379 & 16,860 & 7,527 & $\pm 1,712$ \\
MMF (kg/min) & 0.780 & 11.31 & 3.21 & \pm 1.00 \\
AVGF (kg/min) & 0.31 & 7.49 & 2.10 & \pm 0.63 \\
TMT (min:s) & $2: 17$ & $25: 12$ & $8: 36$ & $\pm 2: 88$ \\
TP (min:s) & $0: 03$ & $15: 44$ & $2: 21$ & $\pm 1: 67$ \\
DT (min:s) & $0: 09$ & $23: 15$ & $2: 68$ & $\pm 1: 49$ \\
TUS (score) & 65.00 & 92.00 & 80.47 & \pm 4.00 \\
UD (score) & 1.00 & 50.00 & 27.60 & \pm 7.27 \\
\hline
\end{tabular}

${ }^{1} \mathrm{AFC}=$ age at first calving: $\mathrm{TD}-\mathrm{MY}=$ milk yield: $305-\mathrm{MY}=$ milk yield at $305 \mathrm{~d}$ : MMF $=$ maximum milk flow; $\mathrm{AVGF}=$ average milk flow; $\mathrm{TMT}=$ total milking time; $\mathrm{TP}=$ time of plateau; $\mathrm{DT}=$ decreasing time; TUS $=$ total udder score; UD = udder depth.

overall reduction in TMT. Nonetheless, with the different ratios, this will occur at the expense of a different variable. An increase in R1 will shorten TMT without placing any constraints on the duration of stable or decreasing flow, acting mainly on the MMF. On the other hand, an increase in R2 will shorten TMT by shortening the phase of plateau. Finally, changes in R3 will modify TMT by constraining the DT. Those measures can be considered complementary, and their changes would shift the release-curve shapes either toward pointy profiles with more or less steep phases of increase and decrease separated by a very short stable flow or conversely toward square profiles with longer stable flows and more or less steep phases of ascension and decline.

To investigate how those flow variables relate to production and functional traits, a third animal model was fitted with the following 8 traits: R1, R2, R3, TMT, 305-MY, 305-SCS, TUS, and UD. The ratios were constructed starting from flow measures, and the model was identical to the 305-d analysis.

Variance Component Estimation. Variance components were estimated using GIBBS2F90 software (Misztal et al., 2002). For each analysis, a single chain consisting of 150,000 iterations was employed, with a burn in period of 30,000 iterations. Convergence was assessed visually from the trace plot. Inferences on the variables were obtained as mean of the respective posterior distributions.

Milkability and Selection. To verify the potential effect of different measures of milkability on production and functional traits in the Italian Brown Swiss population, the selection response for milkability over 5 generations (approximately $30 \mathrm{yr}$ ) was predicted by including flows and time in hypothetical milkability selection indexes. Three different scenarios were executed. In the first one, positive weight (100) was given only to AVGF, and all other flow and time parameters were excluded from the index. This loosely mimics the actual selection for milkability in the Italian Brown Swiss population. In the second scenario, all flow and time parameters were included in the index and weighted accordingly. Finally in the last scenario, flow and time measures were included as ratios and again weighted accordingly. In all cases the overall selection objective was the reduction of TMT with the constraint of maintaining milk production constant and minimizing SCS increase. Weights reported were established through a search grid that produced the best results relative to the overall goal and do not represent a monetary value but rather a measure of relative importance in the index.

Weights in the index were as follows: MMF $(-9.3)$, TMT (-37.5), TP (36.2), and DT (-17.6) for the second scenario and R1 (75.19), R2 (-5.26), and R3 (30.07) for the third scenario. Results are presented as selection response for the correlated production and health traits and TMT. It is important to note that all scenarios played represent an oversimplification of reality because they do not account for the actual direct selection for milk and SCS in the ITE and are aimed at showing the complex nature of the milkability trait along with providing an overall indication of how milk-release parameters could be employed jointly to improve milkability and health parameters. Direct comparison of milkability indexes is beyond the scope of this paper and should account for the overall structure of the ITE.

\section{RESULTS AND DISCUSSION}

\section{Influence of Data Editing}

Rank correlations for a subset including the top 150 sires for the 5 flow traits with models fitted by 
Table 3. Effect of data editing on EBV estimation, rank correlations for a subset including the top 150 sires for the 5 flow traits with data subjected to different editing rules ${ }^{1}$

\begin{tabular}{|c|c|c|c|c|c|c|c|c|}
\hline \multirow[b]{2}{*}{ Trait } & \multirow{2}{*}{$\begin{array}{l}\text { Editing } \\
\text { criterion }\end{array}$} & \multirow[b]{2}{*}{$\mathrm{n}$} & \multicolumn{6}{|c|}{ Editing criterion } \\
\hline & & & (None) & (AVGF) & (MMF) & $(\mathrm{TP})$ & (DT) & (All) \\
\hline \multirow[t]{5}{*}{ MMF } & (TMT) & 41,967 & 96 & 93 & 94 & 94 & 93 & 89 \\
\hline & (AVGF) & 41,301 & & & 92 & 91 & 93 & 91 \\
\hline & (MMF) & 42,705 & & & & 93 & 94 & 89 \\
\hline & $(\mathrm{TP})$ & 41,678 & & & & & 92 & 89 \\
\hline & (DT) & 40,635 & & & & & & 88 \\
\hline \multirow[t]{5}{*}{ AVGF } & (TMT) & 41,967 & 95 & 94 & 93 & 91 & 92 & 87 \\
\hline & (AVGF) & 41,301 & & & 93 & 92 & 93 & 90 \\
\hline & (MMF) & 42,705 & & & & 91 & 93 & 91 \\
\hline & $(\mathrm{TP})$ & 41,678 & & & & & 95 & 90 \\
\hline & (DT) & 40,635 & & & & & & 91 \\
\hline \multirow[t]{5}{*}{$\mathrm{TP}$} & (TMT) & 41,967 & 96 & 93 & 95 & 93 & 94 & 91 \\
\hline & (AVGF) & 41,301 & & & 93 & 95 & 92 & 90 \\
\hline & (MMF) & 42,705 & & & & 91 & 96 & 91 \\
\hline & $(\mathrm{TP})$ & 41,678 & & & & & 95 & 90 \\
\hline & (DT) & 40,635 & & & & & & 92 \\
\hline \multirow[t]{5}{*}{ DT } & (TMT) & 41,967 & 97 & 94 & 92 & 92 & 93 & 89 \\
\hline & (AVGF) & 41,301 & & & 93 & 94 & 91 & 90 \\
\hline & (MMF) & 42,705 & & & & 93 & 95 & 88 \\
\hline & $(\mathrm{TP})$ & 41,678 & & & & & 93 & 89 \\
\hline & (DT) & 40,635 & & & & & & 87 \\
\hline \multirow[t]{5}{*}{ TMT } & (TMT) & 41,967 & 96 & 94 & 92 & 96 & 96 & 88 \\
\hline & (AVGF) & 41,301 & & & 93 & 95 & 92 & 87 \\
\hline & (MMF) & 42,705 & & & & 91 & 96 & 89 \\
\hline & $(\mathrm{TP})$ & 41,678 & & & & & 95 & 89 \\
\hline & (DT) & 40,635 & & & & & & 91 \\
\hline
\end{tabular}

${ }^{1}$ Within parentheses are the editing criteria: $($ None $)=$ all editing criteria retained, $(\mathrm{TMT})=$ criterion on total milking time relaxed; $(\mathrm{AVGF})=$ criterion on average flow relaxed; $(\mathrm{MMF})=$ criterion on maximum flow relaxed; $(\mathrm{TP})=$ criterion on time at plateau relaxed; $(\mathrm{DT})=$ criterion on decreasing time relaxed; $($ All $)=$ data in the whole data set. Without parentheses are the traits in the analyses: MMF = maximum milk flow; $\mathrm{AVGF}=$ average milk flow; $\mathrm{TP}=$ time of plateau; DT $=$ decreasing time; $\mathrm{TMT}=$ total milking time. Column $\mathrm{n}$ represents the individuals entered in each analysis.

relaxing single editing criteria are reported in Table 3. Data were analyzed with the same model used in the single control analysis. Starting from the complete data edited for criteria not related to flow patterns (44,465 individuals), data were eliminated by relaxing editing parameters one at a time. The columns (None) and (All) correspond to the data in the final analysis and the whole data set, respectively. Estimates of variance components for the different models fitted were similar. The removal of single editing criteria had a relatively small influence on the ranking of sires, with rank correlations in the mid and upper nineties. None of the specific editing criteria appeared to have a major effect on the reranking of individuals, although taken as a whole, the editing resulted in sizable changes in correlation of about 10\%. Removing editing criteria cumulatively produced a linear decrease in correlations (data not shown). Changes in correlation were similar across traits. Variance-component estimations were not heavily affected by these editing procedures, and less stringent editing criteria could be used.

\section{Single Control Analysis}

Heritabilities and genetic and phenotypic correlations for the single control analysis are presented in Table 4. Estimated heritabilities for production traits are consistent with estimates obtained for Italian Brown Swiss in routine genetic evaluations (data not shown), indicating that the data structure of this research and the estimates here obtained are representative of the whole population. The TD-MY heritability estimate was consistent with the one recently found by Samoré et al. (2007); as for the TD-SCS heritability estimate $(0.10)$, it is in line with that reported by Samoré et al. (2007) and Boettcher et al. (1998) for the same trait in Brown Swiss and Holsteins, respectively.

Heritability estimates for TMT, AVGF, and MMF ranged from moderate to high, with values of 0.11 , 0.27 , and 0.40 , respectively. This is in agreement with other studies (Gade et al., 2006; Aydin et al., 2008; Guler et al., 2009). As expected, MMF had a strong positive genetic correlation with AVGF (0.96), whereas 
Table 4. Heritabilities (on diagonal) and genetic (above diagonal) and phenotypic (below diagonal) correlations for the single control analysis ${ }^{1}$

\begin{tabular}{lrrrrrrr}
\hline Item & TD-MY & TD-SCS & MMF & AVGF & TP & DT & TMT \\
\hline TD-MY & $\mathbf{0 . 1 2}$ & 0.11 & -0.04 & 0.03 & 0.31 & 0.24 & 0.35 \\
TD-SCS & -0.11 & $\mathbf{0 . 1 4}$ & 0.21 & 0.12 & -0.21 & 0.46 & 0.09 \\
MMF & 0.21 & 0.08 & $\mathbf{0 . 4 0}$ & 0.96 & -0.91 & -0.43 & -0.86 \\
AVGF & 0.44 & -0.01 & 0.83 & $\mathbf{0 . 2 7}$ & -0.84 & -0.58 & -0.90 \\
TP & 0.42 & -0.22 & -0.51 & -0.27 & $\mathbf{0 . 3 2}$ & 0.33 & 0.82 \\
DT & 0.27 & 0.07 & -0.08 & -0.36 & -0.11 & $\mathbf{0 . 0 5}$ & 0.74 \\
TMT & 0.32 & -0.02 & -0.27 & -0.32 & 0.38 & 0.42 & $\mathbf{0 . 1 1}$ \\
\hline
\end{tabular}

${ }^{1} \mathrm{TD}-\mathrm{MY}=$ milk yield; TD-SCS $=$ somatic cell score; $\mathrm{MMF}=$ maximum milk flow; AVGF = average milk flow; $\mathrm{TP}=$ time of plateau; $\mathrm{DT}=$ decreasing time; $\mathrm{TMT}=$ total milking time.

genetic correlations between those flow measures and TMT were negative, with values of -0.86 and -0.90 for MMF and AVGF, respectively, similar to findings in other studies (Gade et al., 2006).

Genetic correlations between TD-MY and TMT and between TD-MY and TP were moderate and positive, with values of 0.35 and 0.31 , respectively, indicating that cows producing a greater amount of milk tend to have a longer TMT. Our estimates agreed with those of Guler et al. (2009) but were less than those found by Sandrucci et al. (2007).

Estimates of genetic correlations between TD-SCS and MMF (0.21) or AVGF (0.12) were positive. However, TD-SCS was negatively correlated with TP $(-0.21)$ and positively correlated with DT (0.46). Grindal and Hillerton (1991) indicated that greater flows are associated with greater sphincters, which facilitate bacterial exposure to the udder tissues, thus causing mastitis, and this could explain the estimates of the present research suggesting that individuals with less flow and a longer TP tend to have lesser SCS and better udder health.

In the current analysis, TD-MY and MMF were essentially uncorrelated, whereas a moderately positive genetic correlation was observed between TD-MY and TD-SCS. These correlations were in contrast with those of Sandrucci et al. (2007), Brown et al. (1986), and Dodenhoff et al. (1999a). Our results suggest a general trend toward greater milk production with lesser SCS when the milking time tends to be longer with lesser MMF and longer TP.

The proportion of additive variance explained and the consistent genetic correlations calculated for the Italian Brown Swiss population would indicate that a selection program for milkability could successfully be implemented using the various flow traits considered here. At present only one of these traits is considered in the ITE, but the inclusion of additional milking variables to better tailor selection for milkability may be considered in the near future.

\section{5-d Analysis}

Heritability estimates and genetic and phenotypic correlations for the complete lactation analysis are presented in Table 5. Heritabilities for TMT, TP, DT, AVGF, and MMF were similar to those estimated with the single control analysis, whereas heritabilities for production traits were greater ( 0.15 for $305-\mathrm{MY}$ and 0.15 for $305-S C S)$.

The heritability for AVGF (0.28) was similar to what was previously found by Santus and Bagnato

Table 5. Heritabilities (on diagonal) and genetic (above diagonal) and phenotypic (below diagonal) correlations for the $305-d$ analysis ${ }^{1}$

\begin{tabular}{lrrrrrrrrr}
\hline Item & $305-\mathrm{MY}$ & \multicolumn{1}{c}{$305-\mathrm{SCS}$} & MMF & AVGF & \multicolumn{1}{c}{ TP } & \multicolumn{1}{c}{ DT } & TMT & TUS & UD \\
\hline 305-MY & $\mathbf{0 . 1 5}$ & 0.11 & 0.12 & 0.18 & 0.20 & 0.17 & 0.18 & 0.14 & -0.40 \\
305-SCS & -0.01 & $\mathbf{0 . 1 5}$ & 0.20 & 0.06 & -0.22 & 0.37 & 0.08 & 0.04 & -0.14 \\
MMF & 0.25 & 0.11 & $\mathbf{0 . 4 1}$ & 0.96 & -0.93 & -0.42 & -0.87 & 0.22 & 0.04 \\
AVGF & 0.26 & 0.12 & 0.81 & $\mathbf{0 . 2 8}$ & -0.83 & -0.6 & -0.90 & 0.25 & 0.04 \\
TP & 0.12 & -0.14 & -0.54 & -0.27 & $\mathbf{0 . 3 1}$ & 0.31 & 0.86 & -0.15 & -0.13 \\
DT & 0.18 & 0.11 & 0.05 & -0.36 & -0.09 & $\mathbf{0 . 0 6}$ & 0.67 & -0.20 & -0.25 \\
TMT & 0.15 & 0.04 & -0.28 & -0.34 & 0.39 & -0.31 & $\mathbf{0 . 1 2}$ & -0.27 & -0.24 \\
TUS & 0.24 & -0.02 & 0.14 & 0.14 & -0.01 & 0.03 & -0.02 & $\mathbf{0 . 2 2}$ & 0.38 \\
UD & -0.14 & -0.01 & 0.03 & 0.01 & -0.08 & -0.05 & -0.05 & 0.29 & $\mathbf{0 . 2 3}$ \\
\hline
\end{tabular}

${ }^{1} 305-\mathrm{MY}=$ milk yield at $305 \mathrm{~d} ; 305-\mathrm{SCS}=$ average SCS; MMF $=$ maximum milk flow; AVGF = average milk flow; $\mathrm{TP}=$ time of plateau; DT $=$ decreasing time; $\mathrm{TMT}=$ total milking time; $\mathrm{TUS}=$ total udder score; UD $=$ udder depth. 
Table 6. Repeatability for flow traits ${ }^{1}$ obtained through a 305-d analysis with a subsample of 4,737 cows with multiple observations

\begin{tabular}{lc}
\hline Trait & Repeatability \\
\hline MMF & 0.61 \\
TP & 0.46 \\
DT & 0.47 \\
AVGF & 0.54 \\
TMT & 0.51 \\
\hline
\end{tabular}

${ }^{1} \mathrm{MMF}=$ maximum milk flow; $\mathrm{TP}=$ time of plateau; $\mathrm{DT}=$ decreasing time; $\mathrm{AVGF}=$ average milk flow; $\mathrm{TMT}=$ total milking time.

(1998). Ilahi and Kadarmideen (2004) estimated AVGF heritabilities in 3 different breeds, reporting values of 0.44, 0.54, and 0.25 for Brown Swiss, Simmental, and Holstein (for this last breed, AVGF was measured on a subjective scale), respectively. Low values of heritability (0.17) were also estimated in primiparous French Holsteins by Rupp and Boichard (1999), with milking speed subjectively scored by the dairy farmers. Finally, in Swiss Holsteins, even lesser estimates of heritability (from 0.03 to 0.098 ) were reported for AVGF recorded electronically using daily random regression methodology for genetic parameter estimation (Karacaören et al., 2006). Samoré et al. (2009) suggested that the large variability of results reported in the literature suggests that the heritability of AVGF largely depends on the method of data collection and the methodology applied to analyze records and that an objective measure would be of great interest to guarantee reliability of collected data and consequent EBV ranking of individuals. The relationship estimated among production, SCS, and milkability traits suggests that selection for increased milk production has produced cows that release milk faster, having high MMF and short TP.

Heritabilities for TUS and UD, the type traits considered, were in agreement with those found by Dal Zotto et al. (2007) in the same population. However, in our analysis, milk flow characteristics (MMF, AVGF) were positively correlated with TUS but essentially un- correlated with UD, in contrast to what was found by Ghiroldi et al. (2005).

In the present study, TP was correlated negatively with TUS $(-0.15)$ and UD $(-0.13)$. Similarly DT was negatively correlated with TUS $(-0.20)$ and UD $(-0.25)$. It is worth mentioning that, based on genetic correlations estimated here, selection for actual TUS would result in udders producing a larger amount of milk in a shorter time. Genetic parameters estimated with a single individual recording of flow measure and single control day production data, or through the use of complete lactation data, appear to be in agreement overall. Greater estimates of heritability were obtained with 305-d data, whereas flow and time parameters remained substantially unchanged.

\section{Estimates of Repeatability}

Estimates of repeatability obtained from a subsample of individuals with multiple records are reported in Table 6. Repeatabilities were moderate to high, ranging from 0.46 for TP to 0.61 for MMF. Repeatability for AVGF, the measure currently employed, was 0.54 . This would, therefore, suggest that, although the collection of repeated flow measures is expected to improve the information precision, the selection performed through a single measure of milk flow would already be effective in improving milk flow traits.

\section{Ratios Analysis}

Heritabilities and correlations for R1, R2, R3, TMT, 305-MY, 305-SCS, TUS, and UD are reported in Table 7. The 3 ratios (R1, R2, and $\mathrm{R} 3$ ) are an attempt to describe a simplified milk-releasing curve. The objective of this analysis was to verify the possibility of selecting for decreased TMT by favoring constant milk release over high maximum flow while still guaranteeing high milk production and lesser SCS.

Table 7. Heritabilities (on diagonal) and genetic (above diagonal) and phenotypic (below diagonal) correlations for the 305-d ratio analysis ${ }^{1}$

\begin{tabular}{lrrrrrrrr}
\hline Item & 305-MY & 305-SCS & \multicolumn{1}{c}{ R1 } & \multicolumn{1}{c}{ R2 } & \multicolumn{1}{c}{ R3 } & TMT & TUS & UD \\
\hline 305-MY & $\mathbf{0 . 1 5}$ & 0.12 & -0.004 & -0.13 & 0.11 & 0.22 & 0.13 & -0.39 \\
305-SCS & -0.02 & $\mathbf{0 . 1 5}$ & 0.11 & 0.32 & -0.04 & 0.05 & 0.09 & -0.18 \\
R1 & 0.05 & 0.10 & $\mathbf{0 . 3 7}$ & 0.76 & 0.83 & -0.92 & 0.21 & 0.06 \\
R2 & -0.03 & 0.09 & 0.28 & $\mathbf{0 . 0 9}$ & 0.51 & -0.65 & 0.14 & 0.04 \\
R3 & -0.04 & -0.01 & 0.43 & 0.02 & $\mathbf{0 . 0 8}$ & -0.83 & 0.34 & 0.16 \\
TMT & -0.21 & 0.07 & -0.55 & -0.03 & -0.23 & $\mathbf{0 . 1 4}$ & -0.24 & -0.21 \\
TUS & 0.22 & -0.01 & 0.12 & 0.04 & 0.05 & -0.03 & $\mathbf{0 . 2 3}$ & 0.37 \\
UD & -0.14 & -0.01 & 0.07 & 0.04 & 0.09 & -0.04 & 0.29 & $\mathbf{0 . 2 4}$ \\
\hline
\end{tabular}

${ }^{1} 305-\mathrm{MY}=$ milk yield at $305 \mathrm{~d} ; 305-\mathrm{SCS}=$ average SCS; R1 = maximum milk flow:total milking time; $\mathrm{R} 2=$ maximum milk flow:time of plateau; R3 = maximum milk flow:decreasing time; TMT $=$ total milking time; TUS $=$ total udder score; UD $=$ udder depth 

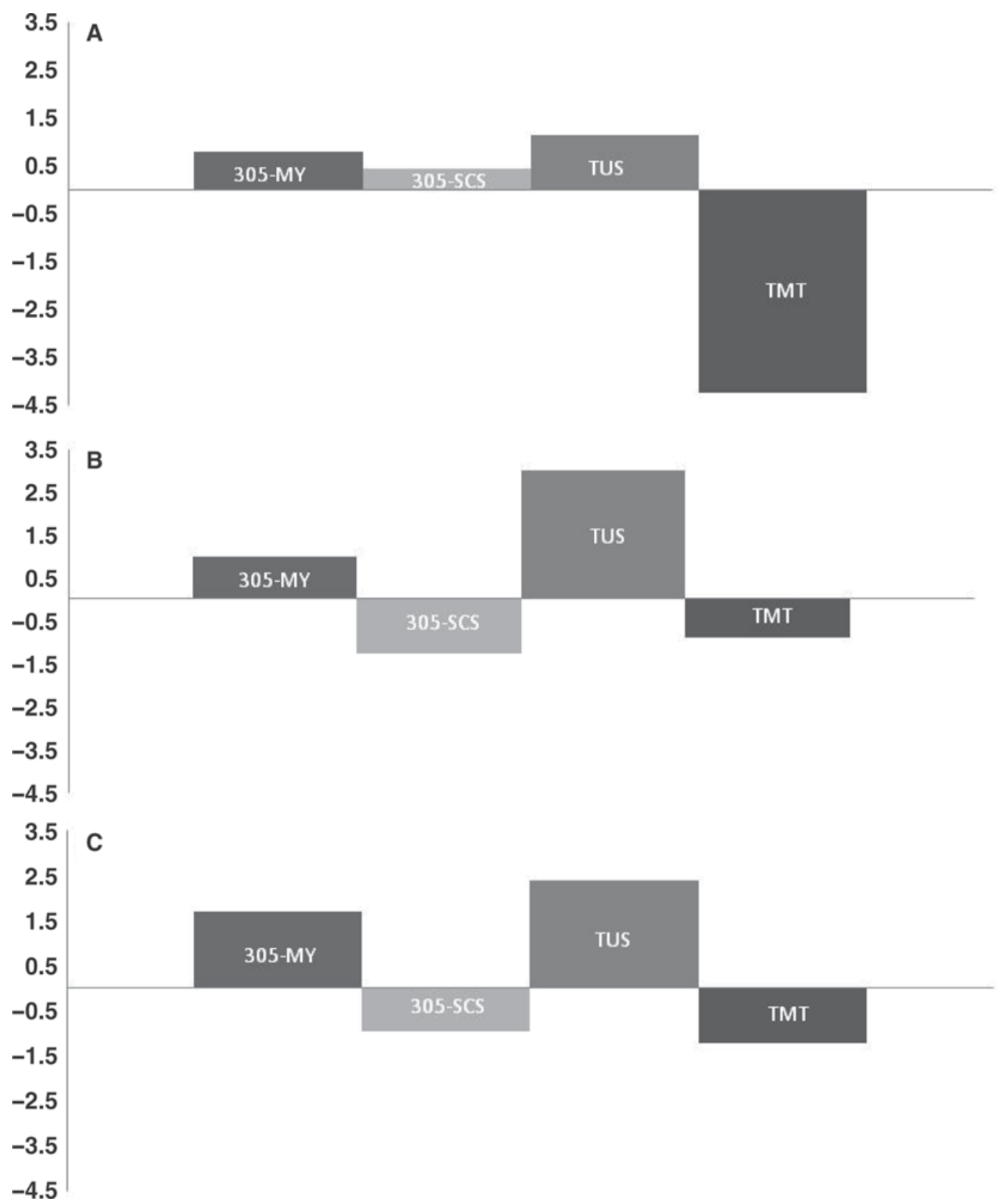

Figure 2. Correlated response (in units of SD) after 5 generations (approximately $30 \mathrm{yr}$ ) of milkability selection. Panel A: Correlated response when selecting for average milk flow. Panel B: Correlated response when selecting for flow and time. Panel C: Correlated response when selecting for ratios. $305-\mathrm{MY}=$ milk yield at $305 \mathrm{~d}$; 305-SCS = average SCS; TUS = total udder score; TMT = total milking time.

The ratio of MMF to TMT (R1) had the greatest heritability (0.37) and showed large positive genetic correlations with R2 (0.76) and R3 (0.83). Ratio R1 was moderately correlated (0.11) with 305-SCS but substantially uncorrelated with 305-MY (-0.004). Although R2 had a moderate negative genetic correlation $(-0.13)$ with $305-\mathrm{MY}$, it showed a stronger positive correlation (0.32) with 305-SCS. Ratio R3 was not correlated with 305-SCS $(-0.04)$, but it was positively correlated (0.11) with 305-MY.

Both R2 and R3 showed lesser heritabilities than R1, with values of 0.09 and 0.08 , respectively, and they were less correlated to each other (0.51) than with R1 (Table 7). These results indicate that the use of flow and time data directly or combined into ratios could lead to the construction of an effective milkability index. 


\section{Milkability and Selection}

Results on selection response predicted from the inclusion of different milkability measures in a milkability index are presented as correlated responses for 305-MY, 305-SCS, TUS, and TMT and expressed in unit changes of standard deviation (Figure 2). When emphasis was placed only on AVGF (Figure 1, panel A), we observed a large reduction in TMT ( $-3.9 \mathrm{SD})$ but a correlated increase of $305-\mathrm{SCS}(0.48 \mathrm{SD})$. On the other hand, when different weights were assigned to all measures of flow and time with the objective of reducing TMT while maintaining milk yield and reducing SCS (Figure 1, panel B), we observed a smaller response in TMT $(-0.09 \mathrm{SD})$ but a significant reduction in SCS (-1.52 SD). A similar pattern was observed when using an index of ratios (Figure 1, panel C). In this case, the selection response predicted was greater for TMT $(-1.44 \mathrm{SD})$, with a corresponding reduction, albeit slightly smaller, for 305-SCS (-0.72 SD).

It is interesting to note that with both selection indexes, a larger increase in total udder score was obtained compared with the use of AVGF alone. This suggests that milkability is not only a reflection of milking time but a more complex trait that can affect animal health, production, and type.

\section{CONCLUSIONS}

The results of this study show that it is possible to use information collected through portable flowmeters to improve milkability traits in the Italian Brown Swiss population. Different studies have estimated milk-release parameters in lactating cows. Most of these studies have relied on small data sets collected for a relatively small number of individuals. In this study a large sample representative of the overall Italian Brown Swiss population was presented. Milk-release characteristics of each cow can be summarized by few heritable aggregated variables. The use of a set of variables, describing the overall patterns of milk removal, represents an effective and advantageous selection strategy compared with the use of a single variable such as average flow. An improved selection strategy including milkability traits, as outlined in this paper, should lower management costs, improve udder health, and consequently decrease veterinary costs associated with udder infection through the indirect favorable selection response predicted for SCS and total udder score. The association between udder infection and milkability traits was estimated here through the indicator of SCS, and further studies should focus directly on the relationships between milkemission measures and clinical mastitis.
In this study genetic parameters were estimated from a single measure of milk flow over the lactation. The availability of repeated measures of milk flow would improve the accuracy of selection; nonetheless, repeatability results from this research obtained on a reduced sample of individuals support the possibility of genetic selection for milk flow traits even with a single measure over the lactation with favorable indirect effect on SCS and udder traits in the Italian Brown Swiss population.

\section{REFERENCES}

Aydin, R., M. Yanar, O. Guler, S. Yuksel, F. Ugur, and L. Turgut. 2008. Study on milkability traits in Brown Swiss cows reared eastern region of Turkey. J. Anim. Vet. Adv. 7:1218-1222.

Bagnato, A., A. Rossoni, C. Maltecca, D. Vigo, and S. Ghiroldi. 2003. Milk emission in different parities in Italian Brown Swiss Cattle. Ital. J. Anim. Sci. 2(Suppl. 1):46-48.

Bagnato, A., A. Rossoni, C. Nicoletti, J. Jacobsen, and E. Santus. 2007. Milkability and temperament MACE correlations and pilot study in dairy cattle populations. Pages 95-97 in Proc. Interbull Mtg., Bulletin No. 37, Dublin, Ireland. Interbull, Uppsala, Sweden.

Boettcher, P. J., J. C. M. Dekkers, and B. W. Kolstad. 1998. Development of an udder health index for sire selection based on somatic cell score, udder conformation, and milking speed. J. Dairy Sci. 81:1157-1168.

Brown, C. A., S. J. Rischette, and L. H. Schultz. 1986. Relationship of milking rate to somatic cell count. J. Dairy Sci. 69:850-854.

Bruckmaier, R. M., E. Rothenanger, and J. M. Blum. 1995. Milking characteristics in dairy cows of different farms and during the course of lactation. J. Anim. Breed. Genet. 112:293-302.

Dal Zotto, R., M. De Marchi, C. Dalvit, M. Cassandro, L. Gallo, P. Carnier, and G. Bittante. 2007. Heritabilities and genetic correlations of body condition score and calving interval with yield, somatic cell score, and linear type traits in Brown Swiss cattle. J. Dairy Sci. 90:5737-5743.

Dodenhoff, J., D. Sprengel, J. Duda, and L. Dempfle. 1999a. Potential use of parameters of the milk flow curve for genetic evaluation of milkability. Pages 131-141 in Proc. Int. Workshop on EU Concerted Action Genetic Improvement of Functional Traits in Cattle (GIFT); Breeding Goals and Selection Schemes, Bulletin No. 23, Wageningen, the Netherlands. Interbull, Uppsala, Sweden.

Dodenhoff, J., D. Sprengel, J. Duda, and L. Dempfle. 1999b. Studies on genetic evaluation of udder health using the Lacto Corder. Zuchtungskunde 71:459-472.

Gade, S., E. Stamer, W. Jungle, and E. Kalm. 2006. Estimates of genetic parameters for milkability from automatic milking. Livest. Sci. 104:135-146.

Ghiroldi, S., C. Nicoletti, E. Santus, A. Rossoni, and A. Bagnato. 2005. ITE: The new selection index for the Italian Brown Swiss. Pages 222-226 in Proc. Interbull Mtg., Bulletin No. 33. Interbull, Uppsala, Sweden.

Grindal, R. J., and J. E. Hillerton. 1991. Influence of milk flow rate on new intramammary infection on dairy cows. J. Dairy Res. 58:263-268.

Groen, A. F., T. Steine, J. J. Colleau, J. Pedersen, J. Pribyl, and N. Reinsch. 1997. Economic values in dairy cattle breeding, with special reference to functional traits. Report of an EAAP working group. Livest. Prod. Sci. 49:1-21.

Guler, O., M. Yanar, R. Aydin, B. Bayram, U. Dogru, and S. Kopuzdu. 2009. Genetic and environmental parameters of milkability traits in Holstein Friesian cows. J. Anim. Vet. Adv. 8:143-147.

Ilahi, H., and H. N. Kadarmideen. 2004. Bayesian segregation analysis of milk flow in Swiss dairy cattle using Gibbs sampling. Genet. Sel. Evol. 36:563-576. 
Interbull. 2008. Announcement of service for workability traits. Accessed July 21, 2008. http://www-interbull.slu.se/service_documentation/Conformation/framesida-conformation.htm

Karacaören, B., F. Jaffrezic, and H. N. Kadarmideen. 2006. Genetic parameters for functional traits in dairy cattle from daily random regression model. J. Dairy Sci. 89:791-798.

Lund, T., F. Miglior, J. C. M. Dekkers, and E. B. Burnside. 1994. Genetic relationships between clinical mastitis, somatic cell count, and udder conformation in Danish Holsteins. Livest. Prod. Sci. $39: 243-251$.

Meyer, K., and B. Burnside. 1987. Scope for a subjective assessment of milking speed. J. Dairy Sci. 70:1061-1068.

Miller, R. H., R. E. Pearson, B. T. Weinland, and L. A. Foulton. 1976. Genetic parameters of several measures of milk flow rate and milking time. J. Dairy Sci. 59:957-964.

Misztal, I., S. Tsuruta, T. Strabel, B. Auvray, T. Druet, and D. H. Lee. 2002. BLUPF90 and related programs (BGF90). Proc. 7th World Cong. Genet. Appl. Livest. Prod., Montpellier, France. CD-ROM communication 28:07. INRA, Paris, France.

Naumann, I., R. D. Fahr, and G. Lengerken. 1998. Relationship between somatic cell count of milk and special parameters of milk flow curves of cows. Arch. Tierz. Dummerstorf 41:237-250.

Prints, D., A. F. Groen, and H. Saatkamp. 2002. Economic value of milkability in dairy cattle. In Animal Breeding and Genetic Group of the Wageningen Institute of Animal Sciences. MS Thesis. Wageningen University, Wageningen, the Netherlands.

Rossoni, A. 2002. Analisi delle curve di emissione del latte in bovine di Razza Bruna. BS Thesis. Università degli Studi di Milano, Milano, Italy.

Rupp, R., and D. Boichard. 1999. Genetic parameters for clinical mastitis, somatic cell score, production, udder type traits, and milking ease in first lactation Holsteins. J. Dairy Sci. 82:2198-2204.

Samoré, A. B., and A. F. Groen. 2006. Proposal of an udder health genetic index for the Italian Holstein Friesian based on first lactation data. Ital. J. Anim. Sci. 5:359-370.

Samoré, A. B., A. F. Groen, P. J. Boettcher, J. Jamrozik, F. Canavesi, and A. Bagnato. 2009. Genetic correlation patterns between so- matic cell count and protein yield in the Italian Holstein-Friesian population. J. Dairy Sci. 91:4013-4021.

Samoré, A. B., C. Romani, A. Rossoni, E. Frigo, O. Pedron, and A. Bagnato. 2007. Genetic parameters for casein and urea content in the Italian Brown Swiss dairy cattle. Ital. J. Anim. Sci. 6(Suppl.1):201-203.

Sandrucci, A., A. Tamburini, L. Bava, and M. Zucali. 2007. Factors affecting milk flow traits in dairy cows: Results of a field study. J. Dairy Sci. 90:1159-1167.

Santus, E., and A. Bagnato. 1998. Genetic parameters estimation for milkability traits recorded with flowmeters in Italian Brown Swiss. Pages 19-22 in Proc. 6th World Cong. Genet. Appl. Livest. Prod. University of Armidale, Australia

Sivarajasingam, S., E. B. Burnside, J. W. Wilton, W. C. Pfeiffer, and D. G. Grieve. 1984. Ranking dairy sires by a linear programming dairy farm model. J. Dairy Sci. 67:3015-3024.

Tancin, V., A. H. Ipema, and P. Hogewefer. 2007. Interaction of somatic cell count and quarter milk flow patterns. J. Dairy Sci. 90:2223-2228.

WMB. 2005. System LactoCorder operating instructions. Accessed July 25, 2009. http://www.lactocorder.ch.

Wiggans, G. R., and G. E. Shook. 1987. A lactation measure of somatic cell count. J. Dairy Sci. 70:2666-2672.

Wiggans, G. R., L. L. M. Thornton, R. R. Neitzel, and N. Gengler. 2007. Short communication: Genetic evaluation of milking speed for Brown Swiss dairy cattle in the United States. J. Dairy Sci. 90:1021-1023.

Zucali, M., L. Bava, A. Sandrucci, A. Tamburini, R. Piccinini, V. Daprà, M. Tonni, and A. Zecconi. 2009. Milk flow pattern, somatic cell count and teat apex score in primiparous dairy cows at the beginning of lactation. Ital. J. Anim. Sci. 8:103-111.

Zwald, N. R., K. A. Weigel, Y. M. Chang, R. D. Welper, and J. S. Clay. 2005. Genetic evaluation of dairy sires for milking duration using electronically recorded milking times of their daughters. J. Dairy Sci. 88:1192-1198. 